\title{
Contributions Regarding the Use of Mechanical Vibrations in Order to Improve the Properties of Steels and Welded Joints Used in Metal Constructions
}

\author{
Gheorghe NOVAC \\ Transilvania University of Brasov, Romania, ghnovac@unitbv.ro \\ Bogdan NOVAC \\ "Ovidius" University of Constanța, Romania, bogdannovac@yahoo.com
}

\begin{abstract}
The paper presents aspects regarding the influence of vibrations on the mechanical properties of welded joints, made with basic materials of Spanish and Romanian origin. In this research is presented the practical way to make the necessary assemblies for the proposed tests. The tests show that vibrations have a significant contribution to the quality of welded joints. This is explained by the appearance of several crystallization centres which makes the structure finer. By using vibrations, the atoms are rearranged in the structure, ensuring a proper de-tensioning. The stresses induced in welded metals are significantly reduced by the use of vibration during welding process. The addition materials have a significant contribution to the emergence of stresses in welded joints as well. These stresses can contribute to the appearance of microstructural constituents with significant hardness. The welding equipment and technologies used also have a significant contribution to the emergence of the remaining stresses. For example, the submerged arc welding technology (SAF) can introduce very high internal stresses. By using vibrations during the welding process, it is achieved a fine structure and a significant reduction of remaining stresses in the welded joints.
\end{abstract}

\section{Keywords}

welded joints, vibrations, low alloy steels, tensile test

\section{Introduction}

The materials that were used in this research are of Romanian origin, but comparatively some behavioural tests on welding were made also on materials of Spanish origin. This type of steels that will be presented in detail in this paper, are steels used in the field of welded constructions and they can be used successfully with welding processes such as MIG-MAG. The presented materials from Romanian origin are both steels and non-ferrous materials. The researched materials comply with the current standards in terms of chemical composition. Due this fact, the chosen materials for this research have a very good welding behaviour. The origin of the Romanian materials is the steel company COS Târgoviște. These materials have the chemical composition shown in Table 1 for steels and in Table 2 for nonferrous alloys [1].

Table 1. Chemical composition of steels from Romania

\begin{tabular}{|c|c|c|c|c|c|c|c|c|c|}
\hline \multirow{2}{*}{ Steel type } & \multicolumn{9}{|c|}{ Chemical composition [\%] } \\
\cline { 2 - 11 } & $\mathrm{C}$ & $\mathrm{Si}$ & $\mathrm{Mn}$ & $\mathrm{P}$ & $\mathrm{S}$ & $\mathrm{Cr}$ & $\mathrm{Ni}$ & $\mathrm{Mo}$ & $\mathrm{Ti}$ \\
\hline E 24-1 & 0.12 & 0.05 & 0.92 & 0.06 & 0.05 & 0.1 & 0.11 & 0.01 & - \\
\hline 18NCD 6 & 0.41 & 0.21 & 0.45 & 0.05 & 0.03 & 1.2 & 1.2 & 0.9 & - \\
\hline 20 M 5 & 0.35 & 0.20 & 1.8 & 0.03 & 0.04 & - & - & - & - \\
\hline 20 MB 5 & 0.24 & 1.38 & 1.45 & 0.04 & 0.05 & 0.2 & 0.4 & 0.20 & - \\
\hline Z 12 CN 18.09 & 0.11 & 0.65 & 0.72 & 0.03 & 0.04 & 18.5 & 8.4 & - & 0.65 \\
\hline Z 6 CNT 18.12B & 0.12 & 0.72 & 0.81 & 0.04 & 0.03 & 18.2 & 10.2 & - & - \\
\hline CC45 & 0.46 & 0.36 & 0.74 & 0.02 & 0.03 & 0.23 & 0.17 & 0.1 & - \\
\hline
\end{tabular}


RECENT, Vol. 21, no. 2(61), 2020

Table 2. Chemical composition of non-ferrous alloys from Romania

\begin{tabular}{|c|c|c|c|c|c|c|c|c|}
\hline \multirow{2}{*}{ Alloy type } & \multicolumn{8}{|c|}{ Chemical composition [\%] } \\
\cline { 2 - 9 } & $\mathrm{Zn}$ & $\mathrm{Mg}$ & $\mathrm{Mn}$ & $\mathrm{P}$ & $\mathrm{S}$ & $\mathrm{Fe}$ & $\mathrm{Al}$ & $\mathrm{Cu}$ \\
\hline Brass & 38.79 & 0.001 & 0.001 & 0.005 & 0.006 & 0.012 & 0.003 & 61.1 \\
\hline Copper & 0.041 & 0.001 & 0.001 & 0.001 & 0.002 & 0.047 & 0.005 & 99.8 \\
\hline Aluminium & 0.072 & 1.28 & 0.541 & 0.012 & - & 0.481 & 93.27 & 4.02 \\
\hline Duralumin & 0.162 & 0.572 & 0.628 & 0.012 & - & 0.476 & 93.77 & 3.97 \\
\hline
\end{tabular}

\section{Experiments and Results}

Ferrous alloys have been carefully developed, minimizing impurities in the chemical composition. For this fact, were used chemical elements that bind these impurities into constituents, which are then removed in the slag. All of this are taking place during thermochemical treatments at temperatures of $840{ }^{\circ} \mathrm{C}$. The ferrous materials presented in Table 1 are used in the field of welded constructions and from the metallurgical point of view, they have the following properties: high ductility, which is maintained in the field of operating temperatures, good thermal conductivity, and a low coefficient of expansion, high friction strength at the level of operating temperatures. They have good casting, plastic deformation and welding properties [5].

Aluminium, copper, brass and duralumin (Table 2) are non-ferrous alloys that are more difficult to weld due to high heat transfer coefficients and due to the formation of the oxides developed during welding. These oxides have high melting temperatures. For these reasons the following recommendations should be taken into consideration when we are welding these non-ferrous alloys:

- Avoiding the choice of gas mixtures containing oxygen;

- Avoiding the formation of fusible compounds in the seam weld, by using chemical elements such as tungsten or vanadium when choosing the electrode;

- The correct choice of the filler material, witch a higher plasticity in the critical temperature range;

- The reduction of the cross-section of the joint.

These non-ferrous alloys used in combination with various elements, generally lead to an improved mechanical strength, they also increase the corrosion resistance in hard environments such as salt water, solvents and fuels [4].

The materials of Spanish origin, used in welding and which have been subjected to testing, are presented in Table 3 for steels and in Table 4 for non-ferrous alloys, together with their chemical properties [1].

Table 3. Chemical composition of steels from Spain

\begin{tabular}{|c|c|c|c|c|c|c|c|c|c|}
\hline & \multicolumn{9}{|c|}{ Chemical composition [\%] } \\
\cline { 2 - 10 } Steel type & $\mathrm{C}$ & $\mathrm{Si}$ & $\mathrm{Mn}$ & $\mathrm{P}$ & $\mathrm{S}$ & $\mathrm{Cr}$ & $\mathrm{Al}$ & $\mathrm{Ni}$ & $\mathrm{Cu}$ \\
\hline Low Alloy & 0.398 & 0.066 & 1.00 & 0.011 & 0.014 & 0.032 & 0.229 & - & 0.264 \\
\hline Ap 04 & 0.083 & 0.017 & 0.281 & 0.006 & 0.005 & 0.033 & 0.072 & - & 0.354 \\
\hline $\begin{array}{c}\text { Stainless Steel } \\
\text { AISI304 }\end{array}$ & 0.045 & 0.027 & 2.34 & 0.026 & 0.013 & 29.01 & - & 8.02 & 0.363 \\
\hline
\end{tabular}

Table 4. Chemical composition of non-ferrous alloys from Spain

\begin{tabular}{|c|c|c|c|c|c|c|c|c|}
\hline \multirow{2}{*}{ Alloy type } & \multicolumn{9}{|c|}{ Chemical composition [\%] } \\
\cline { 2 - 9 } & $\mathrm{Zn}$ & $\mathrm{Mg}$ & $\mathrm{Mn}$ & $\mathrm{P}$ & $\mathrm{S}$ & $\mathrm{Li}$ & $\mathrm{Al}$ & $\mathrm{Cu}$ \\
\hline Brass & 38.79 & 0.001 & 0.001 & 0.005 & 0.006 & - & 0.003 & 61.1 \\
\hline Copper & 0.041 & 0.001 & 0.001 & 0.001 & 0.002 & - & 0.005 & 99.8 \\
\hline Aluminium & 0.07 & 0.303 & 1.11 & 0.012 & - & 1.04 & 96.2 & 0.052 \\
\hline Duralumin & 0.120 & 0.79 & 1.33 & 0.012 & - & 1.09 & 94.9 & 0.049 \\
\hline
\end{tabular}

Romanian steel CC45 and the low alloy steel from Spain, with the chemical composition mentioned in Table 3, were subjected to heat treatments with and without vibrations. The main heat treatments to which these materials have been subjected are: hardening, tempering, annealing, and ageing. 
Both steels hardening was made at the $840{ }^{\circ} \mathrm{C}$. The holding time at the hardening temperature was one hour. After hardening a low tempering was made at $550^{\circ} \mathrm{C}$. They were used mechanical vibrations with a frequency of $80 \mathrm{~Hz}$ and powers of $150 \mathrm{~W}$. On this samples were made acceleration and vibration parameters determinations, hardness testing, tensile testing and resilience [2].

The determinations of accelerations and of the vibration parameters were made on the vibration system with elastic elements. The measurements were necessary in order to be able to establish the optimal values of the accelerations and to obtain maximum effects during the heat treatment processes. As the signal traducers, have been used two accelerometers, which are recording on three directions and as processing software, programs 7709 (data acquisition) and 7770 (FFT analysis). The accelerometers were fixed on the lower plate of the installation, connected directly to the excitation system and on the upper plate, on which the heat treatment oven was installed. The excitation of the system was made with a connecting rod-crank type system, driven at the speed of $3390 \mathrm{rpm}$, with the oven fixed on the vibrating table.

The results are presented in Table 5 [1].

Table 5. Determinations with the accelerometer fixed on the vibrating table connected to the excitation system, at speed $n=3390 \mathrm{rpm}$

\begin{tabular}{|c|c|c|c|c|}
\hline $\begin{array}{c}\text { Harmonic } \\
\text { order }\end{array}$ & $\begin{array}{c}\text { Frequency } \\
{[\mathrm{Hz}]}\end{array}$ & $\begin{array}{c}\mathrm{X} \\
{\left[\mathrm{m} / \mathrm{s}^{2}\right]}\end{array}$ & $\begin{array}{c}\mathrm{Y} \\
{\left[\mathrm{m} / \mathrm{s}^{2}\right]}\end{array}$ & $\begin{array}{c}\mathrm{Z} \\
{\left[\mathrm{m} / \mathrm{s}^{2}\right]}\end{array}$ \\
\hline 1 & 56.95 & 1.030 & 1.050 & 43.500 \\
\hline 1.5 & 85.40 & 0.763 & 0.457 & 0.285 \\
\hline 2 & 113.9 & 1.430 & 4.080 & 15.000 \\
\hline 2.5 & 142.3 & 0.649 & 1.360 & 2.210 \\
\hline 3 & 170.9 & 0.575 & 2.810 & 9.190 \\
\hline 3.5 & 199.4 & 0.358 & 2.840 & 1.930 \\
\hline 4 & 227.8 & 0.348 & 1.110 & 3.640 \\
\hline 4.5 & 256.4 & 0.150 & 0.512 & 2.370 \\
\hline 5 & 284.8 & 1.250 & 0.810 & 5.820 \\
\hline 5.5 & 313.3 & 0.342 & 1.380 & 4.140 \\
\hline 6 & 341.7 & 1.590 & 3.460 & 3.340 \\
\hline 6.5 & 370.2 & 0.472 & 0.626 & 2.840 \\
\hline 7 & 398.7 & 2.390 & 3.180 & 5.850 \\
\hline 7.5 & 427.2 & 1.030 & 1.480 & 0.748 \\
\hline 8 & 455.7 & 2.180 & 1.820 & 1.460 \\
\hline 8.5 & 484.1 & 0.858 & 0.781 & 1.720 \\
\hline
\end{tabular}

The determination of the accelerations on the three directions is necessary to calculate the forces and the vibration parameters acting on the three directions.

The hardness test was performed with a Rockwell hardness tester. The testing was made on a number of four samples, from each material, obtaining the results presented in Table 6 . The Rockwell hardness test was done according to the Spanish norm: UNE-EN ISO 6508/2007 [1].

Table 6. Rockwell hardness values obtained at hardening with and without vibrations

\begin{tabular}{|c|c|c|c|c|c|c|c|c|c|}
\hline \multirow{2}{*}{ Steel type } & \multicolumn{4}{|c|}{ Without vibrations } & \multicolumn{4}{c|}{ With vibrations: f = 80 Hz, P = 150 W } \\
\cline { 2 - 10 } & 1 & 2 & 3 & 4 & 1 & 2 & 3 & 4 & Maximum \\
\hline Low Alloy & 55 & 56 & 57 & 54 & 57 & 58 & 57 & 59 & Max 57 \\
\hline CC45 & 47 & 45 & 44 & 46 & 54 & 55 & 57 & 56 & Max 57 \\
\hline
\end{tabular}

Analysing the results obtained in the hardness tests, without vibrations, it can be said that, the steel of Spanish origin has higher hardness values compared to the Romanian steel. This is due to a more careful elaboration of the steel and due to a lower level of impurities in the structure. When using 
vibrations, a hardness increase is observed for both steels. This hardness increase is due to the influence of vibrations on the mechanisms of transformation of austenite at cooling. Residual austenite, in the presence of vibrations, turns in a larger quantity into martensite. Vibrations facilitate the arrangement of atoms in the structure [3].

The tensile test of metallic materials was made according to the Spanish norm UNE-EN ISO $6891 / 2010$. The results of the tensile tests for the materials shown in Table 6 are presented in Figure 1 for the non-vibrated low alloy steel and in Figure 2 for the vibrated one, both of Spanish origin. Similar results for Romanian non-vibrated CC45 steel are presented in Figure 3, and for vibrated steel in Figure 4 respectively [1].

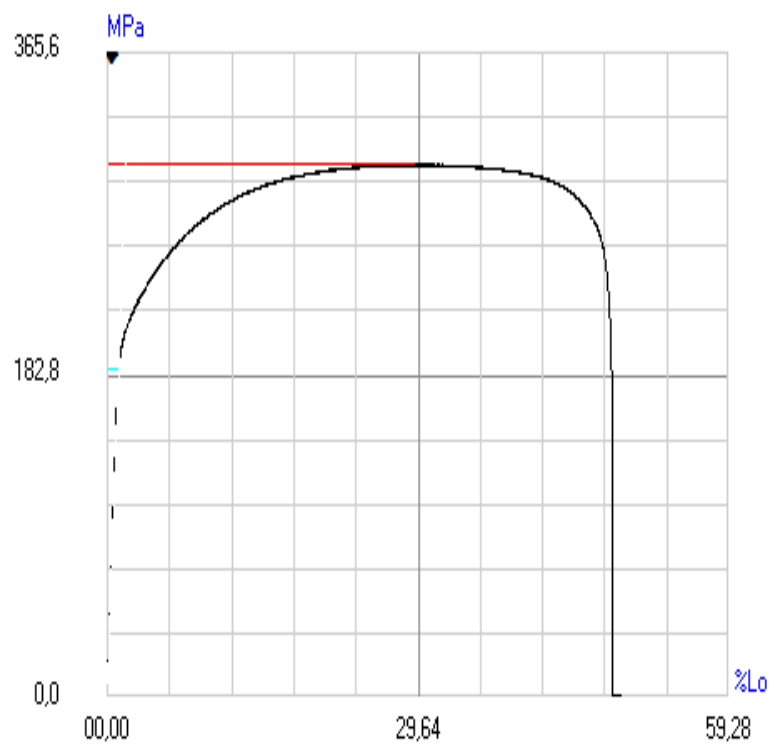

Fig. 1. Variation graphic of tensile strength for non-vibrated Spanish steel

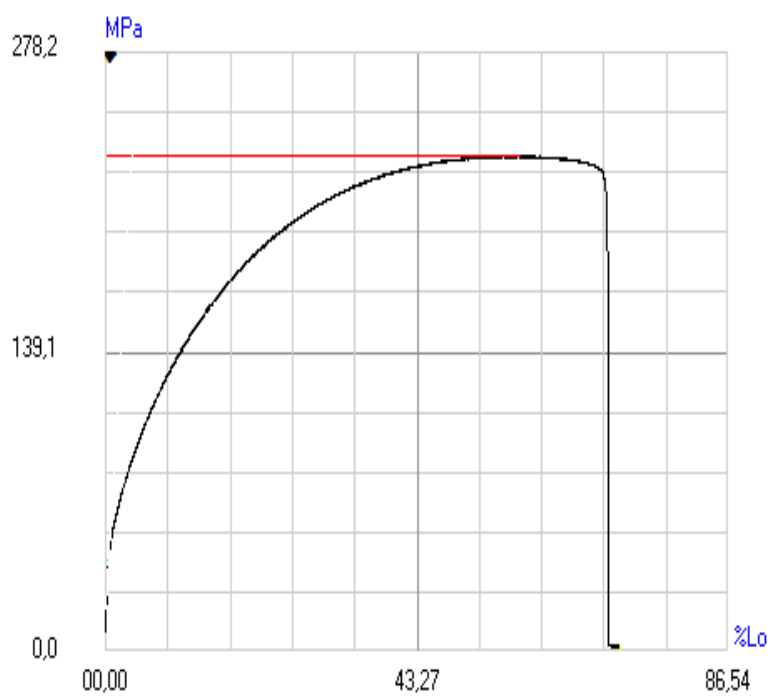

Fig. 3. Variation graphic of tensile strength for non-vibrated CC 45 steel

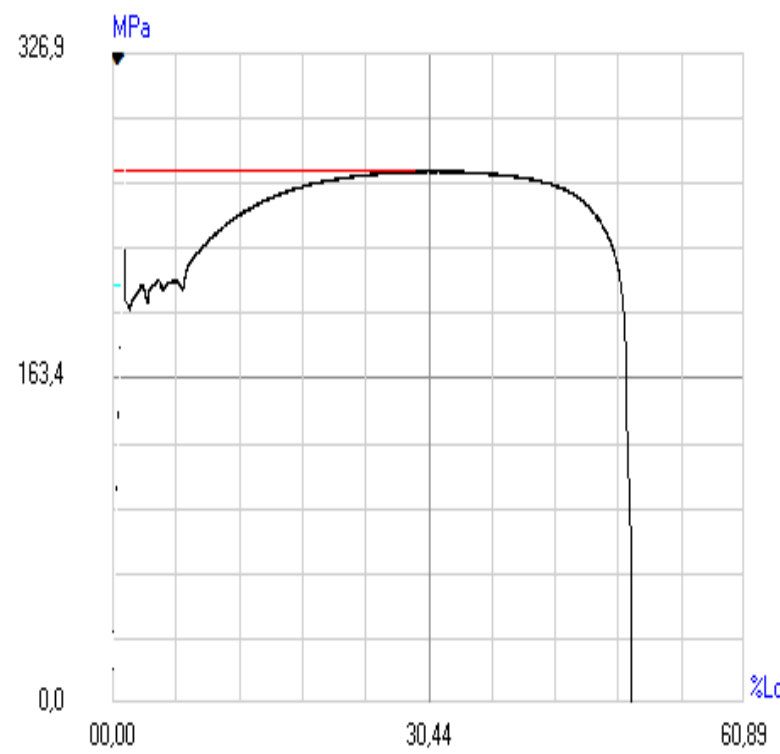

Fig. 2. Variation graphic of the tensile strength for Spanish steel in the presence of vibrations

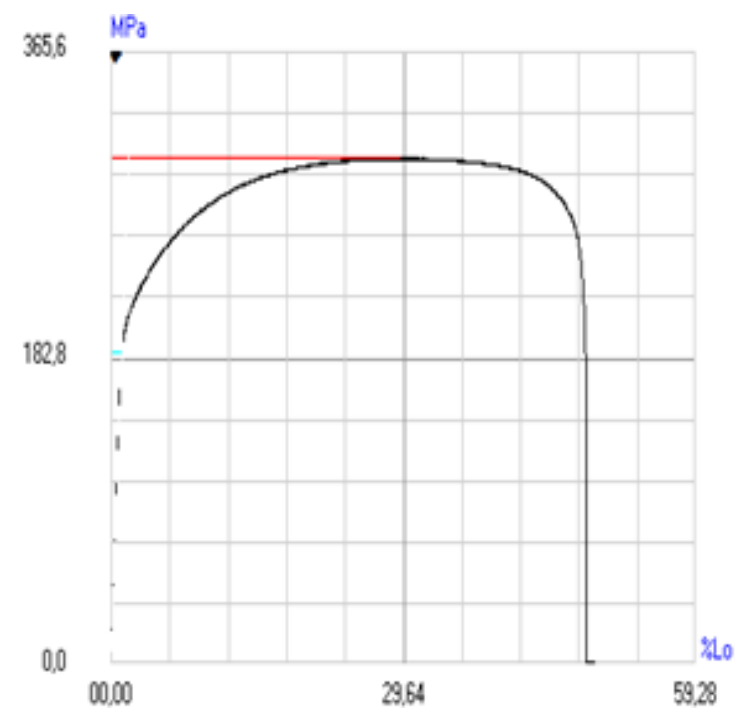

Fig. 4. Variation graphic of the tensile strength for CC 45 steel in the presence of vibrations

The graphs show the tensile force depending on the elongation, $\mathrm{F}(\mathrm{MPa})=\mathrm{L}_{\mathrm{o}}(\%)$.

It can be seen in Figure 1, that the non-vibrated steel has a relatively small portion of the elastic deformations. The portion of plastic deformations is approximately equal to that of vibrated steel. The breakage is almost abrupt in both cases, but more abrupt in the case of non-vibrated steel [3]. In Figure 
2 a deviation of the material rupture from the non-vibrated material is observed. This is due to the arrangement of atoms in the structure. In Figure 3 an increase in the elastic range is observed for nonvibrated CC45 steel, but the breakage is sudden. In Figure 4 is presented the variation of the breaking force for the vibrated CC45 steel. In this case there is a decrease in the area of elastic deformations due to the microstructure obtained from vibrations [1].

The resilience test was performed according to the Spanish standard UNE-EN ISO 14556/2001. The tests were performed on a number of eight samples of each material, and it is observed an increase in resilience (Table 7) [1].

Table 7. Variation of hardening resistance with and without vibrations

\begin{tabular}{|c|c|c|c|c|c|c|c|c|}
\hline & \multicolumn{9}{|c|}{ Without vibrations } & \multicolumn{7}{c|}{ With vibrations: f = 80 Hz, P = 150 W } \\
\cline { 2 - 9 } Steel type & 1 & 2 & 3 & 4 & 1 & 2 & 3 & 4 \\
\cline { 2 - 9 } & 27 & 26 & 24 & 28 & 31 & 33 & 34 & 30 \\
\hline Low Alloy & 25 & 23 & 24 & 26 & 30 & 32 & 29 & 31 \\
\hline
\end{tabular}

\section{Conclusions}

The testing on the two types of materials has highlighted the great advantage of using vibrations during various heat treatments, over the mechanical properties of steels used in welded constructions. The advantage of using vibrations is highlighted during the formation of metallographic structures, but also on the states of residual stresses. This fact is noticed by the reduced deformations that appear at these welded structures, as a result of balancing the residual stresses from these welded joints. Also, by forming several crystallization centres on these welded joints a finer metallographic structure is formed.

Mechanical vibrations produce significant changes especially in the large welded metal constructions. The formation of residual stresses in the welded joints, is also significantly influenced by the applied welding process. MIG-MAG welding technologies create lower residual thermal stresses. Also, laser and electron beam welding technologies, induce lower residual stresses into the welded joint. The presence of vibrations during the heat treatment leads to an increase in the value of the breaking strength from $262 \mathrm{MPa}$ to $293 \mathrm{MPa}$. It also leads to an increase in elongation from $47 \% \mathrm{~L}_{0}$ to $49 \% \mathrm{~L}_{0}$. This phenomenon is due to the stiffening of the steel by heat treatment in the vibrating field, increasing its hardness and increasing the area of plastic deformations. This is due to the transformation in larger quantity, in the presence of vibrations of the residual austenite into martensite.

The tests presented in this paper have the purpose to achieve high quality welded joints.

\section{References}

1. Novac B. (2011): Contribuții privind folosirea vibrațiilor mecanice la tratamentul termic și termochimic al ottelurilor folosite în mecanica fină (Contributions regarding the use of mechanical vibrations at the heat treatment and thermochemical treatment of the irons used in precision mechanics). Ph.D. thesis, Transilvania University of Brasov, Romania, https://ro.scribd.com/doc/262985013/Teza (in Romanian)

2. Graham Kelly S. (2012): Mechanical Vibrations: Theory and Applications, Ed. Cengage Learning, Stamford, USA, ISBN-13: 978-1-4390-6214-2, http://160592857366.free.fr/joe/ebooks/Mechanical\%20Engineering\%20 Books \%20Collection/VIBRATIONS/mechVib\%20theory\%20and\%20applications.pdf

3. Geradin M, Rixen J.D. (2015): Mechanical Vibrations: Theory and Application to Structural Dynamics, Ed. Wiley, West Sussex, United Kingdom, ISBN: 978-1-118-90020-8, https://www.mobt3ath.com/uplode/book/book44219.pdf

4. Zaharia A. (2014): Contribuţii privind caracterizarea îmbinărilor sudate din aliaje de aluminiu AlMg5 (Contributions regarding the characterization of welded joints of aluminum alloys AlMg5). Ph.D. thesis, Transilvania University of Brasov, Romania, https://ro.scribd.com/doc/253158548/Zaharia-Adrian (in Romanian)

5. Novac Gh., Novac B. (2009): Welding of boron and titanium micro alloyed steels. Proceedings of the $1^{\text {st }}$ Int. Conf. on Manufacturing Engineering, Quality and Production Systems (Vol. II), ISSN 1790-2769, ISBN 978-960-474122-9, p. 397-400, http://www.wseas.us/e-library/conferences/2009/brasov/MEQAPS/MEQAPS2-26.pdf 